\title{
Tachycardia- and Bradycardia-Dependent Left Bundle Branch Block Associated with First Degree A-V Block
}

\section{A Study Using His Bundle Electrogram During Carotid Sinus Compression}

\author{
Hiromitsu Tanaka, M.D., Kohji Nuruki, M.D., \\ Yoshifumi Toyama, M.D., Hiromitsu Sasaki, M.D., \\ and Takuya Kanehisa, M.D.
}

\section{SUMmary}

His bundle electrographic examination was performed during carotid sinus compression as well as atrial pacing in a patient who exhibited intermittent left bundle branch block (LBBB) and first degree A-V block. LBBB was observed at the corrected RR intervals below $920 \mathrm{msec}$ and above 1600 msec. The QRS complexes showed normal intraventricular conduction between these 2 values. The critical cycle lengths could not be determined when ordinary RR intervals were used. The HQ interval remained constant at $70 \mathrm{msec}$ regardless of the pattern of intraventricular conduction. It was demonstrated that the patient had both tachycardiaand bradycardia-dependent LBBB with first degree A-V block due to HV block. The authors believe this to be the first case of tachycardiaand bradycardia-dependent bundle branch block studied by His bundle electrography. The important role of $\mathrm{His}$ bundle recordings and carotid sinus compression in the diagnosis of rate dependent intraventricular conduction disturbance was stressed and possible mechanisms underlying this rare condition were discussed.

\section{Additional Indexing Words :}

Corrected RR interval Wedensky phenomenon HV block Supernormal conduction due to generalized diastolic depolarization

COEXISTENGE of tachycardia-dependent and bradycardia-dependent 4 bundle branch block (BBB) in the same patient has been reported only on rare occasions, To our knowledge, 22 such cases have so far appeared in the English literature. ${ }^{1)-5}$ ) The diagnosis of this condition appears to be difficult because it must be differentiated from idioventricular escape beats,

From the First Department of Internal Medicine, Faculty of Medicine, Kagoshima University, Kagoshima, Japan.

Address for reprint request: Hiromitsu Tanaka, M.D., First Department of Internal Medicine, Faculty of Medicine, Kagoshima University, Usuki-cho, Kagoshima 890, Japan.

Received for publication December 24, 1975. 
WPW beats and incomplete bilateral BBB, and because it is necessary to observe ECG's in a relatively wide range of heart rates. This rare condition offers an opportunity to study the electrophysiological properties of diseased conduction system in man.

In this paper, we report the results of an electrophysiological study performed in a patient showing intermittent LBBB to confirm the diagnosis and to explain the mechanism of tachycardia-dependent and bradycardiadependent LBBB.

\section{Material and Methods}

Case history:

A 52-year-old man was referred to Kagoshima University Hospital for a detailed evaluation of his arrhythmia on May 9, 1973. He was in good health until the age of 40 when he noticed an irregular pulse. In December 1972, the patient was told that he had LBBB. In April 1973, he had an attack of palpitation followed by syncope. He had a pneumonectomy for pulmonary tuberculosis at the age of 49. He suffered from malaria and dengue fever in 1944.

On admission, the pulse was $60 / \mathrm{min}$ and regular. The blood pressure was $130 / 60 \mathrm{mmHg}$. A grade 1 systolic murmur was audible at the apex. There were no signs of congestive heart failure. The chest X-ray showed slight cardiomegaly with normal lung fields. Liver function tests, serum electrolytes and CBC were all within normal range.

Electrocardiographic findings:

Three types of QRS complexes were observed (Figs. 1 and 2). These were designated type 1 and type 2 LBBB and normal QRS, respectively. Type 1 LBBB was characterized by (1) a QRS duration of $0.15 \mathrm{sec}$, (2) a mean $Q R S$ axis of about $0^{\circ}$, and (3) notched $R$ waves in V6. Type 2 LBBB had the following patterns: (1) QRS complexes of $0.16 \mathrm{sec}$ duration, (2) a mean QRS axis of around $-45^{\circ}$, and (3) a notched $R$ in V6 lower than that of type 1 LBBB. Normal QRS complexes had a duration of $0.10 \mathrm{sec}$ and a normal mean $Q R S$ axis of $90^{\circ}$. PQ interval was $0.24 \mathrm{sec}$. These observations may suggest that type 2 LBBB shows a complete block in the left bundle branch, whereas type 1 LBBB shows an almost complete block in this bundle branch.

Electrophysiological methods:

His bundle electrograms (HBE's) were recorded by the method originally introduced by Scherlag and Damato. ${ }^{6)} \mathrm{A}$ no. 6 tripolar probe (Castillo) was used. HBE's were recorded on a multichannel recorder (rectigraph and visigraph, San-ei Sokki Co, Ltd) with the frequency response set at $500 \mathrm{~Hz}$ and the time constant at $0.003 \mathrm{sec}$. The paper speed was either 100 or $125 \mathrm{~mm} / \mathrm{sec}$. Atrial pacing was performed with a second catheter positioned against the lateral wall of the right atrium, using a Medtronic $5880 \mathrm{~A}$ demand pacemaker. The following intervals were measured: The PA and $\mathrm{AH}$ intervals: These intervals were measured according to Narula et al." The HQ interval: the interval between the 

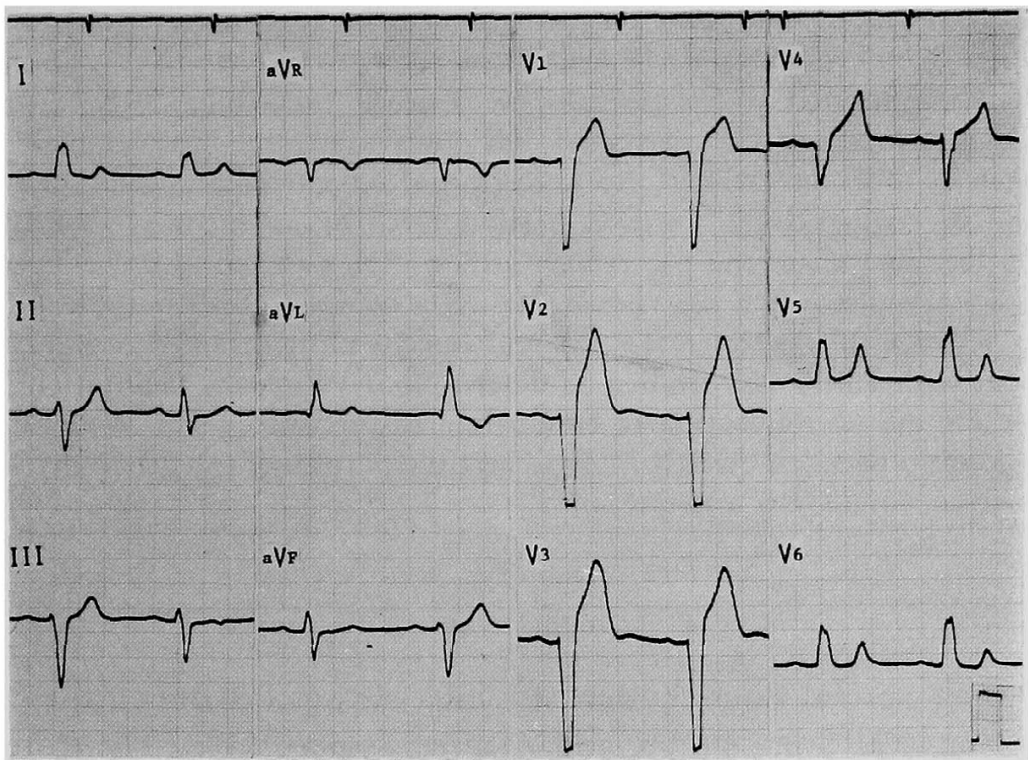

Fig. 1. ECG showing type 1 and type 2 LBBB. The first beats of leads aVR, aVL, and aVF and the second beats of leads I, II, III, V1 through V6 show type $1 \mathrm{LBBB}$, and all other beats show type $2 \mathrm{LBBB}$. PQ interval is $0.24 \mathrm{sec}$.

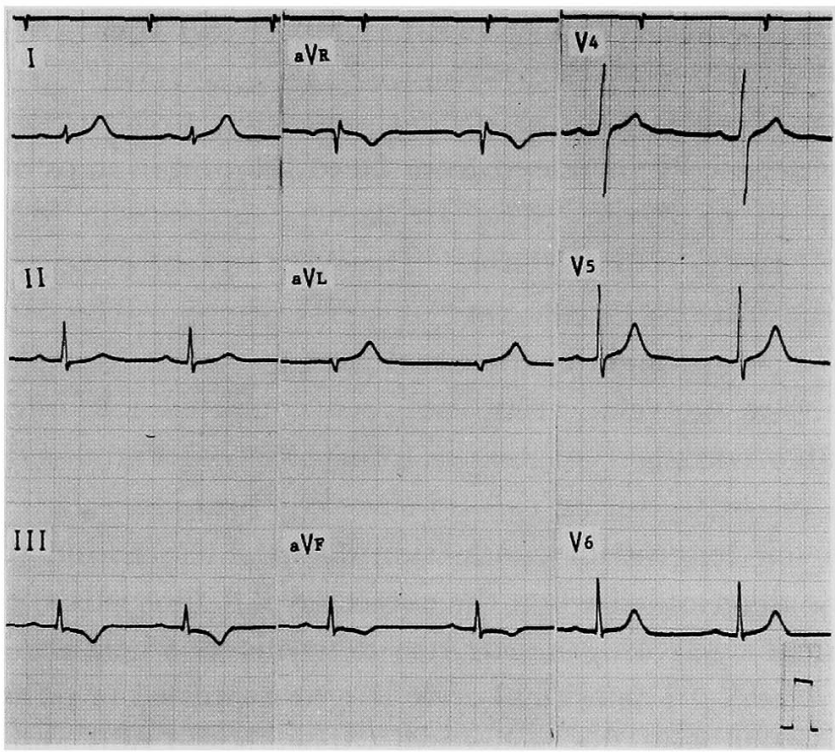

Fig. 2. ECG showing normal intraventricular conduction. ST depression and $\mathrm{T}$ wave inversion are seen in leads III and aVF. PQ interval is $0.24 \mathrm{sec}$. 
onset of the His deflection and the earliest onset of ventricular depolarization, as determined from either the surface ECG or the $V$ wave in HBE. The ordinary RR interval: the interval between the onset of the preceding QRS and that of a given QRS complex. The corrected $R R$ interval: ${ }^{8)}$ the interval measured (1) from the onset of the preceding $Q R S$ to the initial deflection of a given $Q R S$ complex when the preceding beat showed a normal $Q R S$ or an incomplete BBB, or (2) from the termination of the preceding QRS complex to the initial deflection of a given QRS complex when the former showed a complete BBB pattern. The relationship between the corrected RR interval and the pattern of QRS complex following a beat with LBBB was studied to determine if Wedensky facilitation ${ }^{9)}$ was responsible for the normalization of conduction disturbance. For Wedensky effect, the relationship between the RR interval and the pattern of QRS complex following a beat with normal QRS was examined.

\section{Results}

During normal sinus rhythm (PP interval was $820 \mathrm{msec}$ ), the $\mathrm{PA}, \mathrm{AH}$, and $H Q$ intervals were 40,96 , and $70 \mathrm{msec}$, respectively. Therefore, it was suggested that the PQ prolongation was due to HV block." The HBE recorded during carotid sinus compression is shown in Fig. 3. The first and second beats show type 2 LBBB, the third, fourth, seventh, and tenth beats show type $1 \mathrm{LBBB}$, while the remaining beats show normal QRS complexes. The beat with type 2 LBBB (the second beat) has a corrected $R R$ interval of $840 \mathrm{msec}$, those with type 1 LBBB show the corrected RR intervals of 912 , 920,2264 , and $1740 \mathrm{msec}$, and those with a normal QRS were accompanied by values between 1020 and $1480 \mathrm{msec}$. The HQ interval is almost constant and measures $70 \mathrm{msec}$. Atrial pacing was then performed. The rate of pacing was sequentially increased from 80 to $180 / \mathrm{min}$ in steps of 10 beats per minute every 10 to $20 \mathrm{sec}$. The atrioventricular conduction showed 1:1 response up to the rate of $180 / \mathrm{min}$. The $\mathrm{AH}$ interval increased normally in response to the increase in the rate of atrial pacing. The $\mathrm{HQ}$ interval remained at $70 \mathrm{msec}$ throughout the atrial pacing.

Fig. 4 shows the relationship between corrected $R R$ intervals and the 3 types of QRS complexes obtained from 150 consecutive QRS complexes in the HBE's recorded during carotid sinus compression. It is clearly shown that critical cycle lengths for conduction disturbances within the left bundle branch can be determined when the corrected RR intervals are used. However the critical cycle length was not determined when the ordinary RR intervals were used. The critical cycle length expressed in terms of corrected RR interval is $920 \mathrm{msec}$ for tachycardia-dependent LBBB and around 1600 msec for bradycardia-dependent LBBB. Type 1 and type 2 LBBB were observed when corrected RR interval was between 600 and $920 \mathrm{msec}$. Although 

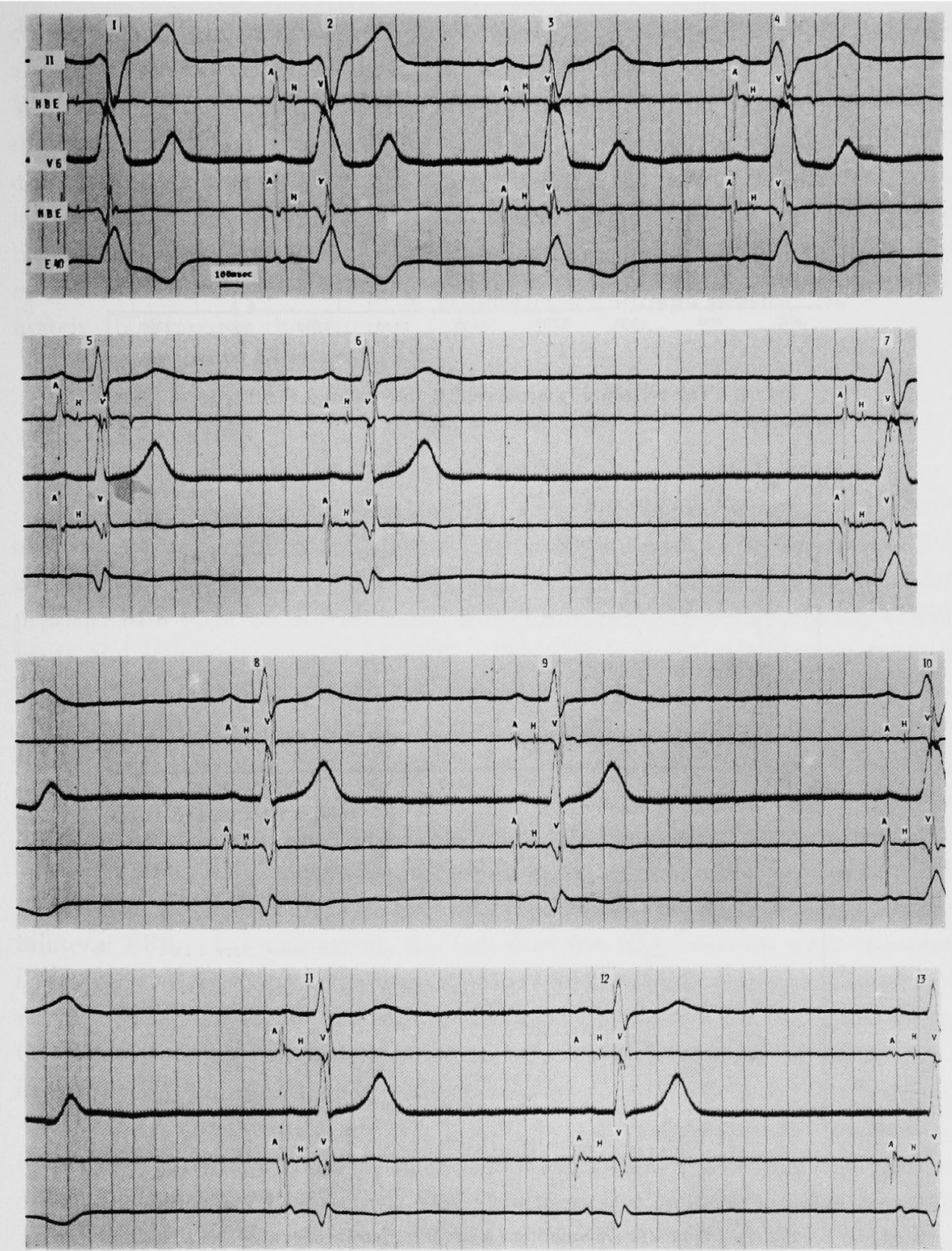

Fig. 3. Continuous HBE recording together with ECG (leads II, V6 and esophageal lead) taken during carotid sinus compression. Figures shown at the top of each QRS show beat numbers. The 3rd, 4th, 7th, and 10 th beats with type $1 \mathrm{LBBB}$ have corrected RR intervals of 912, 920, 2264, and 1740 msec, respectively. The second beat showing type $2 \mathrm{LBBB}$ has a corrected RR interval of $840 \mathrm{msec}$. Normal $Q R S$ complexes have corrected RR intervals of $1020,1240,1200,1348,1320,1400$, and $1480 \mathrm{msec}$, respectively. 


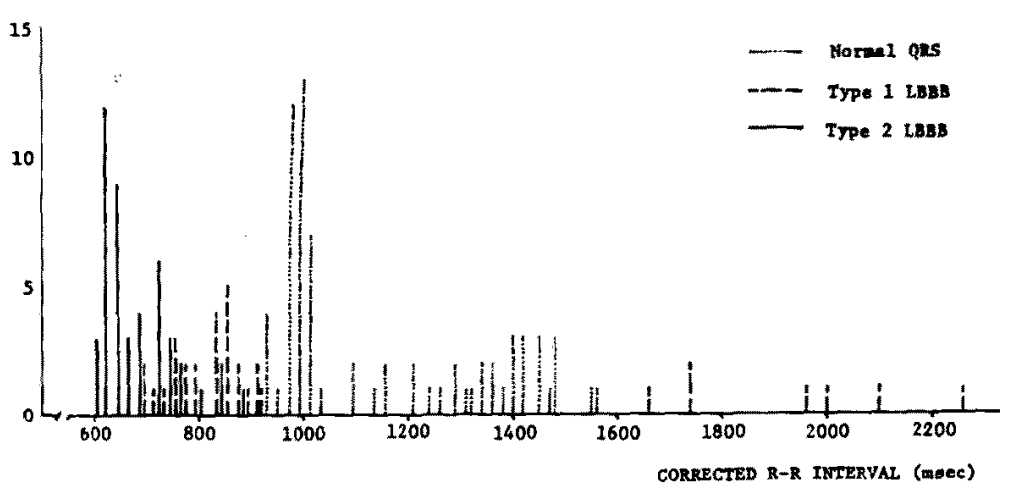

Fig. 4. The relationship between $R R$ interval and the 3 types of $Q R S$ complexes.

(A)
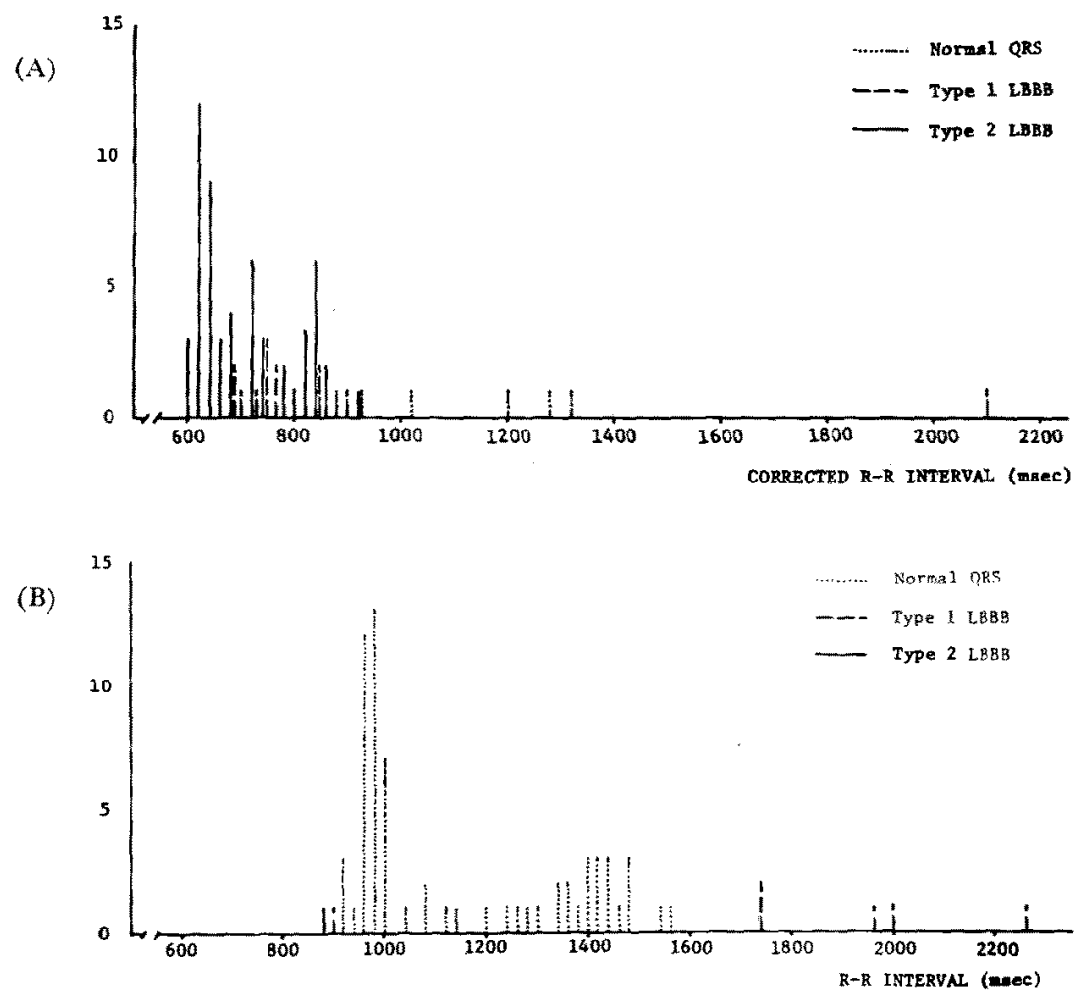

Fig. 5. Wedensky facilitation (A) and Wedensky effect (B).

type 2 LBBB appeared after shorter cycle lengths than type 1 , individual critical cycle lengths for these 2 types could not be determined. Thus, it was demonstrated that this patient had tachycardia- and bradycardia-dependent LBBB with first degree AV block due to HV block. Fig. 5A shows Wedensky facilitation in the left bundle branch. Normal QRS appeared when the 
corrected RR interval was between 920 and $1320 \mathrm{msec}$, whereas type $1 \mathrm{LBBB}$ appeared when corrected RR interval was 2100 msec. Fig. 5B shows Wedensky effect in the left bundle branch. Normal QRS was observed when the cycle length was between 920 and $1560 \mathrm{msec}$, whereas type 1 LBBB was observed when the cycle length was between 1740 and 2260 msec. Thus, it may well be conjectured that conduction disturbance in the left bundle branch in this patient could be improved by Wedensky facilitation as well as effect. The duration was longer than $1320 \mathrm{msec}$ in the former and approximately $1600 \mathrm{msec}$ in the latter.

\section{Discussion}

(1) The diagnosis of rate dependent BBB

The diagnosis of rate dependent $\mathrm{BBB}$, especially of bradycardia-dependent ones, seems to be difficult. Massumi ${ }^{1)}$ and Rosenbaum et al $^{31}$ proposed the criteria for the diagnosis of bradycardia-dependent BBB. Bradycardia-dependent BBB must be differentiated from idioventricular escape beats, WPW beats and incomplete bilateral BBB. The HQ interval may be constant in the presence of both normal intraventricular conduction and $\mathrm{BBB}$ in the case of tachycardia- and bradycardia-dependent $\mathrm{BBB}$, whereas it may be variable in the case of escape beat(s), WPW beat(s), and also incomplete bilateral BBB where a normal QRS appears when the degree of conduction disturbances in the left and the right bundle branches become almost identical. ${ }^{10}$ ) Therefore, His bundle electrography can easily differentiate rate dependent BBB from idioventricular escape beat(s), WPW beat(s) and incomplete bilateral BBB. In our patient, the fact that the HQ intervals were constant irrespective of QRS patterns indicates that all the QRS complexes observed were not idioventricular but supraventricular in origin. To our knowledge, this is the first case of tachycardia- and bradycardia-dependent LBBB confirmed by His bundle electrography.

In $\mathrm{BBB}$, the blocked part of a bundle branch is depolarized retrogradely by an impulse which has depolarized the contralateral ventricle through the other bundle branch and then has traversed the interventricular septum. Thus the blocked part of a bundle branch would be depolarized during the last phase of ventricular activation. Therefore, the interval at which 2 impulses reach the blocked part of the bundle branch must be measured from the termination of the preceding beat with $\mathrm{BBB}$ to the beginning of the QRS in question. In 1971, Tokunaga et al ${ }^{8}$ proposed " the corrected RR interval " to determine the critical cycle length in intermittent right BBB. In our case, the critical cycle lengths were clearly determined using this concept 
as shown in Fig. 4.

One of the reason why only a few cases of tachycardia- and bradycardiadependent $B B B$ have been reported in the literature appears to be the necessity for ECG recordings in a wide range of heart rates in order to detect this condition. Carotid sinus compression is a simple method to induce slowing of the heart rate. It is basically important that the procedure itself has no direct effect on the His-Purkinje system. The actions of cholinergic stimuli on the His-Purkinje system are controversial. ${ }^{11)}$ Some investigators have indicated that cells of the specialized conduction system below the AV junction are not affected by acetylcholine or vagal stimulation.12),13) In contrast, Bailey et $\mathrm{al}^{14)}$ showed that acetylcholine enhanced conduction in spontaneously firing Purkinje fibers. In either case, it appears that acetylcholine at least does not depress His-Purkinje conduction. In the intact dog heart, Varghese et al $^{15}$ demonstrated that acetylcholine and vagal stimulation sufficient to produce cardiac arrest had no effect on antegrade and retrograde His-Purkinje conduction. Although the evidence that acetylcholine and vagal stimulation do not depress the conduction in a diseased part of the His-Purkinje system is lacking, it is likely that vagal stimulation itself does not depress His-Purkinje conduction. Therefore, carotid sinus compression seems to be an adequate method for detecting rate dependent intraventricular conduction disturbances.

(2) The possible mechanisms of tachycardia- and bradycardia-dependent BBB

The dispute on the underlying mechanisms for this condition is still unsettled, and several theories have to be considered. Rosenbaum et al ${ }^{3}$ ) thought that the concept of phase 3 black related to prolonged recovery in one population of cells and phase 4 block related to slight hypopolarization plus spontaneous diastolic depolarization in another population of cells best explain tachycardia- and bradycardia-dependent BBB. El-Scherif et al16) proposed that tachycardia-dependent block in the canine proximal HisPurkinje system was based on a time-dependent response of Purkinje fibers partially depolarized by an increase in extracellular concentration of potassium ion, and that bradycardia-dependent block was explained by a slight to moderate decrease of resting potential, a normal slope of phase 4 depolarization and reduced membrane responsiveness associated with a shift of the threshold potential toward zero. Friedberg ${ }^{17}$ proposed the concept of Wedensky phenomenon to explain the mechanism of bradycardia-dependent LBBB in a patient showing Wenckebach AV block. He postulated that the electrotonic potential induced by the preceding impulse raised the resting potential of the zone of block nearer to threshold potential resulting in normalization of the conduction. Singer et $\mathrm{al}^{18}$ ) showed that, after the onset of generalized diastolic 
depolarization in deteriorated Purkinje fibers, the entire voltage time course of diastolic potential was altered and the maximum value might be reached quite late in the diastolic interval. This suggests that the deteriorated fibers can respond to impulses reaching only during a limited period in late diastole. This phenomenon can explain so-called supernormal conduction. Sarachek ${ }^{19}$ ) used this concept for explaining the mechanism of bradycardia-dependent $B B B$ seen in his patient.

Conduction disturbances in the His-Purkinje system resulting from shortening of the cycle length may be caused by one or a combination of the following factors:20) (1) reduced membrane potential due to incomplete repolarization or due to low resting potential, (2) depressed responsiveness, (3) decreased $\mathrm{dV} / \mathrm{dt}$ independent of the level of resting membrane potential at excitation, ${ }^{21}$ and (4) impedance mismatch. ${ }^{22}$ Conduction disturbances accompanying prolongation of cycle length can be explained by one or a combination of the following factors: (1) reduced membrane potential due to development of phase 4 depolarization in a latent pacemaker, ${ }^{18}$ (2) stretch of the conduction system secondary to transient enlargement in cardiac chamber resulting from bradycardia, (3) transient ischemia in the conduction system due to bradycardia or due to vagal influence accompanying bradycardia, ${ }^{231}$ and (4) Wedensky phenomenon. Theoretically, coexistence of tachycardia- and bradycardia-dependent $\mathrm{BBB}$ may be caused by a combination of 2 or more factors each of which is included in the causes of tachycardiadependent $\mathrm{BBB}$ and bradycardia-dependent $\mathrm{BBB}$ as mentioned above. The concept of supernormal conduction due to generalized diastolic depolarization can also reasonably explain tachycardia- and bradycardia-dependent BBB. Different mechanisms may operate in the development of tachycardia- and bradycardia-dependent $\mathrm{BBB}$ having different etiology. In our case, the etiology of the conduction disturbance remains unknown.

\section{ACKNOWLEDGEMENT}

The authors gratefully acknowledge the critical review of the manuscript by Dr. Yoshio Watanabe.

\section{REFERENCES}

1. Massumi RA: Bradycardia dependent bundle branch block. A critique and proposed criteria. Girculation 38: 1066, 1968

2. El-Sherif N: Tachycardia-dependent versus bradycardia-dependent intermittent bundle branch block. Brit Heart J 34: 167, 1972

3. Rosenbaum MB, Elizzari MV, Lazzaro JO, Halpern MS, Nau GJ, Levi RJ: The mechanism 
of intermittent bundle branch block. Relationship to prolonged recovery, hypopolarization and spontaneous diastolic depolarization. Chest 63: 666, 1973

4. Barold SS, Schamroth L: Tachycardia-dependent left bundle branch block associated with bradycardia-dependent left bundle branch block. Circulation 48: 216, 1973

5. El-Sherif N: Tachycardia- and bradycardia-dependent bundle branch block after acute myocardial ischemia. Brit Heart J 36: 291, 1974

6. Scherlag BJ, Lau SH, Helfant RH, Stein E, Berkowitz W, Damato AN: Catheter technique for the recording of His bundle electrograms in man. Circulation 39: 13, 1969

7. Narula OS, Scherlag BJ, Samet P, Javier RP: Atrioventricular block. Localization and classification by $\mathrm{His}$ bundle recordings. Am J Med 50: 146, 1971

8. Tokunaga T, Terasaka T, Hisamatsu M, Mae R, Minato T, Moriwaki S, Saito D, Haraoka $\mathrm{S}$ : An electrocardiographic study on intermittent bundle branch block. Jap Circulat $\mathrm{J} 35$ : 1231,1971

9. Friedberg HD: Observations on the duration of Wedensky facilitation in the left bundle branch. J Electrocardiol 5: 185, 1972

10. Schloff LD, Adler L, Donoso E, Friedberg CK: Bilateral bundle-branch block. Clinical and electrocardiographic aspects. Circulation 35: 790, 1967

11. Higgins CB, Vatner SF, Braunwald E: Parasympathetic control of the heart. Pharmacol Reviews 25: 119, 1973

12. Hoffman BF, Cranefield PF: Electrophysiology of the Heart. McGraw-Hill Book Co, New York, 1960

13. Moe GK, Mendez G: Functional block in the intraventricular conduction system. Circulation 43: 949, 1971

14. Bailey JC, Greenspan K, Elizari MV, Anderson GJ, Fisch C: Effects of acetylcholine on automaticity and conduction in the proximal portion of the His-Purkinje specialized conduction system of the dog. Circulat Res 30:210, 1972

15. Varghese PJ, Damato AN, Lau SH, Akhtar M, Bobb GA: The effect of heart rate, acetylcholine, and vagal stimulation on antegrade and retrograde His-Purkinje conduction in the intact heart. Am Heart J 86: 203, 1973

16. El-Scherif N, Scherlag B: Pathophysiology of tachycardia- and bradycardia-dependent block in the canine proximal His-Purkinje system after acute myocardial ischemia. Am J Cardiol 33: 529,1974

17. Friedberg HD: Mechanism of the Wedensky phenomena in the left bundle branch. Am J Cardiol 27: 698, 1971

18. Singer DH, Lazzra R, Hoffman BF : Interrelationships between automaticity and conduction in Purkinje fibers. Circulat Res 21: 537, 1967

19. Sarachek NS: Bradycardia-dependent bundle branch block. Relation to supernormal conduction and phase 4 depolarization. Am J Cardiol 25: 727, 1970

20. Singer DH, Ten Eick RE: Aberrancy. Electrophysiological aspects. Am J Cardiol 28: 381,1971

21. Bigger JT, Bassett AL, Hoffman BF: Electrophysiological effects of diphenylhydantoin on canine Purkinje fibers. Circulat Res 22: 221, 1968

22. Neus $H$, Thormann $J$, Sclepper $M$ : Electrophysiological findings in frequency-dependent left bundle branch block. Brit Heart J 36: 888, 1974

23. Vesell $\mathbf{H}$, Lowen $\mathrm{G}$ : Bundle-branch block on cardiac slowing at a critical slow heart rate. Am Heart J 66: 329, 1963 